\title{
PULMONARY EMBOLISM DURING OPERATION
}

\author{
A.C. Enright, G.R.C. Quartey And J.D. MCQueEn
}

\begin{abstract}
A case of intra-operative pulmonary embolism is reported. Though this is evidently a rare occurrence, the diagnosis should be seriously considered when unexplained hypoxia occurs during operation. Appropriate investigation and treatment can then be initiated promptly.
\end{abstract}

PULMONARY EMBOLISM must occur very rarely during operation as a search of the available literature disclosed no published cases. Recently we encountered a case which forms the basis for this report.

\section{CASE REPORT}

A 67-year-old man was first admitted to the Neurology Service for evaluation of a five-month history of progressive gait disturbance and intermittent headaches. He also described episodes of severe nausea, anorexia and vertigo.

Physical examination revealed an alert but somewhat vague patient, rather slow in recounting history. He exhibited a broad-based gait and stance and tended to fall toward the left side. There was marked cerebellar ataxia in the left limbs, with a lesser degree of ataxia in the right limbs. The muscle stretch reflexes were symmetrically brisk with bilaterally flexor plantar responses.

The clinical impression of a cerebellar mass lesion was confirmed by the CT scan and vertebral angiography. It was considered that the lesion was quite likely a haemangioblastoma of the vermis encroaching on the cerebellar hemispheres. The investigations also showed that he had polycythaemia, which is a recognized concomitant of cerebellar haemangioblastoma.

\section{ANaEsthesia and Operation}

Following premedication with intramuscular pentobarbitone, morphine sulphate and gly-

Angela C. Enright, M.B., F.R.C.P.(C), Department of Anaesthesia; Gilbert R.C. Quartey, M.B. F.R.C.S.(C), and J. Donald McQueen, M.D., F.R.C.S.(C) Department of Clinical Neurological Sciences; University Hospital, Saskatoon, Saskatchewan, S7N 0W8.

Reprint request to: Dr. A.C. Enright.

Canad. Anaesth. Soc. J., vol. 27, no. 1, Jinuary 1980 copyrrolate one hour before operation anaesthesia was induced with Innovar ${ }^{\natural}$, fentanyl, thiopentone and pancuronium and maintained with nitrous oxide, oxygen, pancuronium and fentanyl. Monitoring during operation included arterial and central venous pressure lines, oesophageal stethoscope and precordial Doppler probe. The patient was placed in the prone position with the head elevated approximately $40 \mathrm{de}$ grees from the horizontal plane.

During removal of bone for the posterior fossa cranitomy the patient developed sinus tachycardia. A sample of arterial blood drawn for blood gas analysis was noted to be dark. $\mathrm{F}_{\mathrm{I}_{2}}$ was promptly increased to 0.5 while awaiting the blood gas results. $\mathrm{Pa}_{\mathrm{O}_{2}}$ was $5.32 \mathrm{kPa}(40 \mathrm{~mm}$ $\mathrm{Hg}$ ). $\mathrm{FI}_{\mathrm{U}_{2}}$ was further increased to 1.0. (See Table I for $\mathrm{Fl}_{\mathrm{O}_{2}}$ and $\mathrm{Pa}_{\left(\mathrm{C}_{2}\right.}$ during operation.) $\mathrm{A}$ thorough search for possible cause of the severe sustained hypoxia, including chest X-ray, was unrewarding. Strong consideration was given to termination of the procedure. However, there was a gradual rise in $\mathrm{Pa}_{\mathrm{U}_{2}}$ and it was decided to continue.

Surgical exposure revealed a large tumour cyst in the midline with a mural nodule attached to the anterosuperior aspect of the wall. Approximately $30 \mathrm{ml}$ of dark brown cyst fluid was removed and the nodule was excised. Histological examination confirmed a capillary haemangioblastoma.

Toward the end of the procedure another episode of severe hypoxia occurred (Table I). This time the operation was quickly completed and the patient was returned to the intensive care unit after tracheal extubation. He was alert and neurologically normal.

Thirty minutes after arrival in the intensive care unit he developed a supraventricular tachycardia which rapidly converted to atrial fbrillation. He became cyanosed, apnoeic, hypotensive and lost consciousness. The trachea was promptly reintubated and he was ventilated 65 
TABLE I

\begin{tabular}{lccccc}
\hline & & $\begin{array}{c}\mathrm{cH}^{+} \\
\mathrm{nmol} / 1\end{array}$ & $(\mathrm{pH})$ & $\begin{array}{c}\mathrm{PaO}_{2} \\
\mathrm{kPa}(\mathrm{Torr})\end{array}$ & $\begin{array}{c}\mathrm{PaCO}_{\mathrm{O}_{2}} \\
\mathrm{kPa}(\mathrm{Torr})\end{array}$ \\
\hline Steady state & 0.35 & 34.67 & $(7.46)$ & $15.43(116)$ & $2.79(21)$ \\
& 0.35 & 33.88 & $(7.47)$ & $13.43(101)$ & $3.06(23)$ \\
Episode 1 & 0.30 & 41.69 & $(7.38)$ & $5.32(40)$ & $3.99(30)$ \\
& 1.00 & 40.74 & $(7.39)$ & $4.66(35)$ & $3.59(27)$ \\
Steady state & 1.00 & 45.71 & $(7.34)$ & $11.97(90)$ & $4.79(36)$ \\
& 0.60 & 40.74 & $(7.39)$ & $12.50(94)$ & $3.59(27)$ \\
& 0.50 & 40.74 & $(7.39)$ & $11.57(87)$ & $3.86(29)$ \\
Episode 2 & 0.50 & 48.98 & $(7.31)$ & $6.92(52)$ & $3.59(27)$ \\
& 0.60 & 45.71 & $(7.34)$ & $8.38(63)$ & $4.39(33)$ \\
& 0.70 & 42.66 & $(7.37)$ & $11.57(87)$ & $3.59(27)$ \\
& 0.70 & 35.48 & $(7.45)$ & $18.75(141)$ & $4.39(33)$ \\
\hline
\end{tabular}

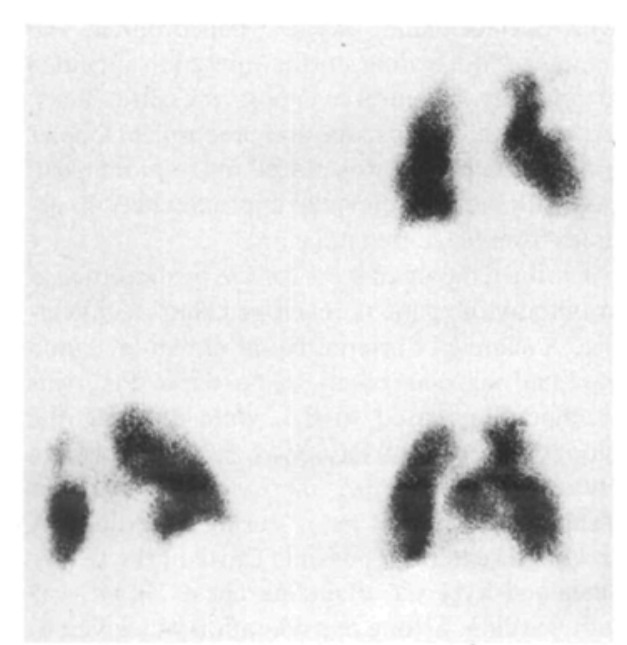

FIGURE 1 Lung scans showing multiple perfusion defects in both lung fields, day of operation.

with 100 per cent oxygen by a mechanical ventilator. He rapidly regained consciousness. The electro-cardiogram at that time showed minor ST changes, thought to be related to the rapid heart rate. Intravenous digitalization was begun. Repeated chest $\mathrm{X}$-ray revealed features consistent with mild fluid overload. This was treated with furosemide. The central venous pressure had risen from 16 to $30 \mathrm{~cm} \mathrm{H} \mathrm{H}_{2} \mathrm{O}$ at this time. A diagnosis of recurrent pulmonary embolism was strongly suspected. Lung scans (Figure 1) showed multiple filling defects consistent with this diagnosis.

Because of the contraindications to heparinization and the severity of the recurring episodes of hypoxia, it was felt that inferior vena cava ligation was the treatment of choice.

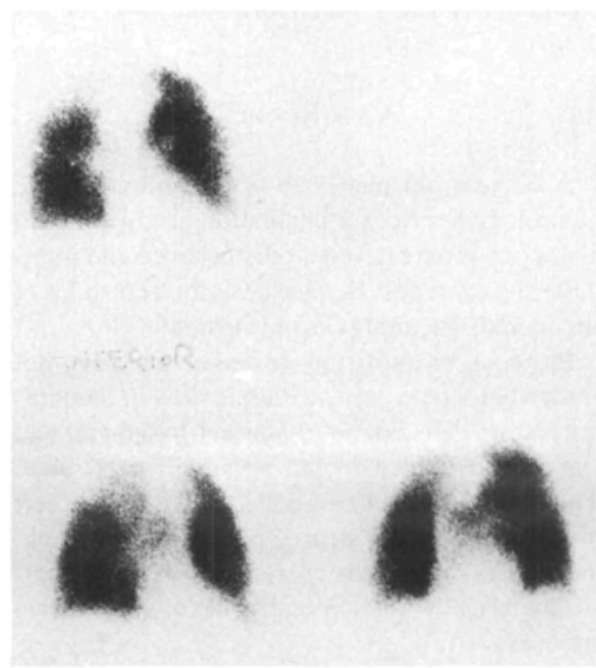

Figure 2 Lung scans showing partial resolution of lung lesions, two days post-operative.

Subsequent to this procedure the patient developed no further respiratory problems and made an excellent post-operative recovery. Additional lung scans two days and one week after operation (Figures 2 and 3 ) revealed progressive resolution of the lung lesions.

\section{Discussion}

This unusual case posed a diagnostic problem. Air embolism was considered during operation, but seemed unlikely, as the first hypoxic episode occurred when no significant venous channels had been exposed. Further, the position of the patient made the diagnosis unlikely. No changes in the Doppler monitoring or blood pressure were noted. No cardiac murmurs were evident. A 


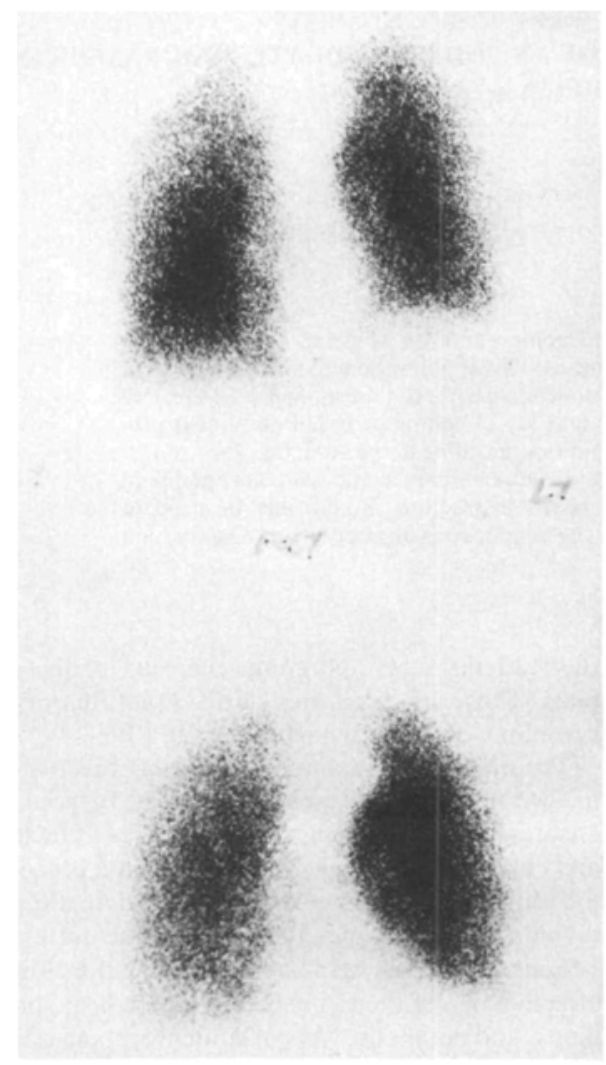

Figure 3 Lung scans one week after operation. Lungs appear normal. primary lung lesion, for instance a pneumothorax, or defects in the gas delivery sys. tems were conclusively ruled out. Tumor embolism was not seriously considered because the lesion had not been exposed or manipulated at the time of the first episode. The correct diagnosis was strongly considered only when the episode occurred in the intensive care unit.

Although unproven by venography it is probably fair to state that phlebothrombosis in this patient's legs or pelvis with subsequent pulmonary embolism was the cause of his problem. We feel that the patient's inactivity while undergoing investigations was a significant aetiological factor. His inactivity was at least partly provoked by ataxia and vertigo. Polycythaemia may well have been a contributory factor. Certainly no further hypoxic episodes occurred following inferior vena caval plication.

The question of pre-operative low dose heparinization can legitimately be raised in such cases. This form of therapy has been controversial in neurosurgical practice. Particularly with potentially haemorrhagic posterior fossa lesions, the severe risks far outweigh any possible benefits.

It is clear, finally, that pulmonary embolism during operation, although rare, should be seriously considered when unexplained hypoxia occurs during operation. Only then will the appropriate investigation and treatment be carried out promptly and major catastrophes be averted.

\section{RÉSUMÉ}

Les auteurs rapportent un cas d'embolie pulmonaire per-opératorie. Bien que cette complication soit rare, elle doit être envisagée lorsq'une hypoxie inexpliquée survient pendant la chirurgie. Un diagnostic précoce peut alors être fait et le traitement mis en marche rapidement. 